\title{
Reading units that include interword spaces: Filling spaces around a letter can facilitate letter detection
}

\author{
ALICE F. HEALY \\ University of Colorado, Boulder, Colorado \\ and \\ THOMAS F. CUNNINGHAM \\ St. Lawrence University, Canton, New York
}

\begin{abstract}
College students searched for the letter "a" in prose passages typed normally, with an asterisk (Experiments 1 and 2) or the letter " $x$ " (Experiment 3) replacing every interword space, or with asterisks replacing only some of the interword spaces (Experiment 2). Contrary to predictions based on masking through lateral interference but consistent with predictions based on studies of eye movement monitoring and unitization, asterisks or instances of the letter " $x$ " surrounding the word "a" actually made the letter "a" easier to detect in that word, but generally not in other words in the text. It is concluded that for very common words, reading units may extend beyond the word boundary to include the surrounding interword spaces.
\end{abstract}

Earlier studies involving a letter detection task have provided evidence that readers use processing units greater than the letter (see Healy, 1994, for a summary). Some of these studies have even provided evidence that readers use processing units greater than the word (e.g., Drewnowski \& Healy, 1977). In the present study, we used the letter detection task to provide stronger evidence for this claim, by showing that reading units can extend beyond the word boundary to include the interword spaces.

In the letter detection task, subjects read prose passages and circle instances of a target letter. It has been found that subjects make a large percentage of letter detection errors on common words, especially on very frequent function words, such as "the," even when the passage is scrambled

This work was supported in part by Army Research Institute Contracts DASW01-96-K-0010, DASW01-99-K-0002, and DASW01-03-K-0002 and Army Research Office Grant DAAG55-98-1-0214 to the University of Colorado (A.F.H., principal investigator) and by a faculty research grant from St. Lawrence University to T.F.C. We are indebted to Charlotte Healy for conducting a preliminary experiment in this series, to Kenneth Paap, Seth Greenberg, and Robert Lorch for helpful comments about this research, to Kimberly Smith for help in developing test materials and in assisting with the administration of Experiments 1 and 2, to James Parker for help in data tabulation in Experiment 1, to James Kole for help in data tabulation in Experiment 2, and to Michael Mund for help in data tabulation in Experiment 3. A summary of Experiment 1 was included as part of a poster presented at the 1998 Annual Meeting of the Psychonomic Society (Healy, Cunningham, \& Healy, 1998). Correspondence concerning this article should be sent either to A. F. Healy, Department of Psychology, University of Colorado, 345 UCB, Boulder, CO 80309-0345 (email: ahealy@psych.colorado.edu) or to T. F. Cunningham, Department of Psychology, St. Lawrence University, Canton, NY 13617 (e-mail: tcun@stlawu.edu). so those words are not predictable from the surrounding semantic and syntactic context (see, e.g., Healy, 1976). This effect is diminished or eliminated if the familiar visual configuration of the word is disturbed by misspelling it (e.g., Cunningham, Healy, Kanengiser, Chizzick, \& Willitts, 1988; Healy \& Drewnowski, 1983), by typing alternate letters in uppercase (e.g., Drewnowski \& Healy, 1977), by using an unfamiliar font (Schneider \& Healy, 1993), or by placing asterisks between successive letters (Healy, Conboy, \& Drewnowski, 1987, Experiment 1).

To account for the results obtained using the letter detection task, Healy and Drewnowski (1983; see also Drewnowski \& Healy, 1977, and Healy, 1976) proposed a set of five unitization hypotheses: (1) Processing occurs within a hierarchy of levels defined in terms of the units used at each level (e.g., letters, syllables, words, and phrases). (2) Processing at the various levels occurs in parallel (i.e., simultaneously), rather than serially. (3) The familiarity of a particular unit at a given level facilitates its processing. For example, words that occur frequently in the language may be processed more readily at the word level than are words that occur less frequently in the language. (4) Identification - and thus, detection - of a particular unit at a given level results when processing of that unit has been completed. (5) When a unit at a given level and in a given location in the text has been processed to the point of identification, the reader does not continue processing its component subunits at lower levels of the hierarchy but, rather, moves on to process the subsequent location in the text for reading units at all levels of the hierarchy. For example, if a particular word has been identified, the reader will move on to process the next word in the text, 
even if all of the component letters in the word have not yet reached the point of identification. In a letter detection task, such identification of higher level units before the identification of letter units results in letter detection errors.

Subsequently, another hypothesis - the parafoveal processing hypothesis - was added to the set of unitization hypotheses by Hadley and Healy (1991) to account for the finding that the high rate of letter detection errors on frequent function words does not occur when those words are fixated. According to this hypothesis, higher level units can be identified before their component letter units more readily if the identification occurs in the parafovea. Consistent with this hypothesis is the finding in studies of eye movements that word identification is facilitated by partial parafoveal letter identification (e.g., Rayner, McConkie, \& Zola, 1980).

An alternative explanation for the finding of many letter detection errors on frequent function words has been proposed by Koriat and Greenberg (see Koriat \& Greenberg, 1994, for a summary). According to this structural account, subjects make letter detection errors on function words because these words recede into the background during semantic processing of the text, although they play an important role, earlier in processing, in establishing the structural frame of the text. By this account, the letter detection errors reflect processes that occur after lexical identification and establishment of the structural frame have been completed. Thus, this account cogently explains the effect of word function on letter detection errors but cannot explain the effects of any visual manipulations on letter detection errors, because such manipulations necessarily influence processes occurring before or during, but not after, lexical identification.

Letter detection studies have shown that the size of the reading unit depends on the age and reading ability of the subjects (e.g., Drewnowski, 1978, 1981; Greenberg, Koriat, \& Vellutino, 1998). In an earlier study (Cunningham et al., 1988, Experiments 1 and 2), we demonstrated that third-grade children, seventh-grade children, and adult college students all made greater percentages of letter detection errors in prose passages when the target letter "a" occurred in the very common word "a" (Kučera \& Francis, 1967) than when it occurred embedded within other words (e.g., "walked"). This finding was explained by proposing that children in the third grade and beyond use reading units that extend beyond the word boundary. In contrast, children in the first grade showed a reversal of this error trend, with a smaller percentage of letter detection errors on the word "a" than on other words. The finding for firstgrade children is consistent with expectations based purely on visual factors (not unitization), because the letter "a" is surrounded by blank spaces for the word "a," which should facilitate its detection, whereas it is surrounded by letters when embedded in other words, which should inhibit its detection.

The aim of the present study was to provide stronger evidence that the large percentage of letter detection er- rors on the very common word "a" by experienced readers is attributable to the fact that they can read that word in units that extend beyond the word boundary to include the interword spaces. That is, the reading unit for the word "a" may be the letter surrounded by blank spaces (a ) rather than the letter alone (a). Because the word "a" is the only one in the English language that contains a single small letter (the only other single-letter word is "I," which is always capitalized), it could be identified in the parafovea as a blank-small-letter-blank pattern with only the general shape of the letter (i.e., the fact that it is small and is not an ascender or descender) sufficient for lexical identification. Thus, processing the individual letter in the fovea would not be necessary for lexical identification. Eye movement studies provide ample testimony that frequent function words are often identified in the parafovea and, thus, not fixated when reading (see, e.g., O’Regan, 1979; Rayner \& Pollatsek, 1989; Rayner, Sereno, Morris, Schmauder, \& Clifton, 1989).

To test the hypothesis that interword spaces can be part of the reading unit for the very common word "a," so that the reading unit and the letter are not identical, the present study made use of a manipulation that altered the visual characteristics of the text surrounding the word "a" by replacing the interword spaces with irrelevant characters. Interpolating such characters should disrupt features of the normal configuration of the reading units (e.g., word shape and word length). Previous eye-movement-monitoring studies using similar manipulations involving filled interword spaces have shown that these manipulations disrupt eye movement patterns by decreasing reading rate and saccade length (e.g., Morris, Rayner, \& Pollatsek, 1990; Pollatsek \& Rayner, 1982) and by increasing the number of fixations (e.g., Pollatsek \& Rayner, 1982), although these studies have not addressed the question of whether there is a differential effect of these manipulations on highfrequency function words, such as "a." In a previous letter detection study by Healy et al. (1987, Experiment 2), this manipulation of replacing the interword spaces with extraneous asterisks was used with the target letter " $h$ " and the frequent function word "the" to provide evidence that the word "the" is read in a unit that extends beyond the word boundary into the interword spaces. In an earlier study by Healy and Drewnowski (1983, Experiment 3), similar evidence was provided when plus signs $(+)$ replaced the interword spaces with the target letter " $n$ " and the frequent function word "and." In those studies, the target letters did not occur next to the interword spaces or next to the extraneous characters in the frequent function words. However, in the present study, the same manipulation of replacing the interword spaces with asterisks involved placing asterisks around the target letter itself in the test word "a," because that word consists of only a single letter. The present study, thus, provided a more exacting test of the hypothesis that word boundaries may include interword spaces.

According to the unitization account, subjects who read the word " $a$ " in a unit extending beyond the word 
boundary should make a smaller percentage of letter detection errors on that word in a given passage when asterisks occur in the interword spaces than when the same passage is typed normally with blank interword spaces, because the asterisks should disrupt the familiar visual configuration of the larger unit. This prediction is counterintuitive, because it would be expected that asterisks should serve to hide or mask the target letter through lateral interference (see, e.g., Estes, Allmeyer, \& Reder, 1976), rather than increase its visual saliency. Indeed, an earlier study by Healy et al. (1987, Experiment 1) demonstrated a decrease in letter detection errors when lateral interference was reduced by inserting blank spaces between all the characters in a continuous text. Thus, the present study would provide a strong confirmation of the unitization account if it were to be found that subjects do, in fact, make a smaller percentage of letter detection errors on the word "a" when the passage occurs with asterisks replacing the interword spaces than when the passage is typed normally with blank interword spaces. Such a counterintuitive finding could perhaps be explained by arguing that subjects read the passage more slowly and/or with less attention to the content when the passage is typed with asterisks replacing the interword spaces. However, that alternative explanation would also lead to the hypothesis that the asterisk format would lead subjects to make a smaller percentage of letter detection errors overall on other words containing the target letter.

\section{EXPERIMENT 1}

Experiment 1 compared passages typed normally with those typed with asterisks replacing every interword space.

\section{Method}

Subjects. The subjects were 36 students ( 20 women and 16 men) from St. Lawrence University, who were enrolled in two different sections of an introductory psychology course and who volunteered to participate for extra class credit. Two additional students were tested, but their data were not employed, because they failed to follow instructions.

Design. A $2 \times 2 \times 2$ mixed factorial design was employed. There was one between-subjects variable, passage format order (normal first, asterisk first), and two within-subjects variables, passage format (normal and asterisk) and type of test word ("a" and other words). The dependent variable examined was the percentage of letter detection errors (i.e., misses). (As in previous letter detection experiments, false alarm errors in which subjects circled an incorrect letter were extremely rare and will not be considered here.)

Materials. Each subject saw two passages. These passages had been employed earlier in Experiments 1 and 2 of the study by Cunningham et al. (1988) and included only common words known even to first-grade children. (See the Appendix for the two passages with their comprehension questions.) They were prepared in Times New Roman type font, with a font size of 14 . One passage (Passage A) consisted of 64 words, whereas the other (Passage B) had 49 words. The word "a" appeared eight times in each passage, and 16 other words in each passage contained the letter "a" (e.g., "walked"). The word "a" never occurred as the first or last word of a sentence.

The passages were prepared in two formats. The normal format was typed in the regular fashion, with no asterisks present, whereas the asterisk format was typed with an asterisk replacing every interword space (e.g., It*was *a*hot*day. *The*girl*took). There were no extra asterisks at the end or beginning of a line, and there was only a single space (or an asterisk) separating a period from the first word of the next sentence. The word "a" never occurred as the first or the last word on a given line.

The subjects were given photocopies of the two passages. Passage format order was counterbalanced across subjects, with half of the subjects receiving the normal format first and half receiving the asterisk format first. Passage order was also counterbalanced across subjects within each passage format order group; that is, half of the subjects in each passage format order group saw the passages in the order Passage A followed by Passage B, and the other half saw the passages in the opposite order.

All the subjects received a test packet that included (1) a first passage, followed on the next page by a comprehension test that consisted of four multiple-choice questions, and (2) a second passage, followed on the next page by a comprehension test that also included four multiple-choice questions.

Procedure. The subjects were tested in two separate groups in the same classroom at different times. The students were assigned to passage format order groups and to passage order subgroups according to a fixed rotation depending on their time of arrival for testing.

The instructions that the subjects read specified that they were to read the passages at their normal reading speed and to circle the letter "a" whenever they came to it. The instructions also specified that if the subjects ever realized that they had missed an "a" in a previous word, they should not go back to circle it. Furthermore, the instructions indicated that the subjects were not expected to get every "a" and should, therefore, not slow down in order to do so.

The subjects were also told in advance that they would be given comprehension questions following each passage and that they should make sure that they read each passage for meaning.

\section{Results and Discussion}

Performance on the four multiple-choice comprehension questions was very good. The mean percentage of comprehension errors was $6.6 \%$. Performance based on pure guessing would yield an error rate of $75 \%$.

The results of Experiment 1 are summarized in Table 1 in terms of percentages of letter detection errors as a function of passage format and type of test word. There was a significant main effect of passage format $[F(1,34)=4.95$, $\left.M S_{\mathrm{e}}=309, p<.05\right]$. The subjects made more errors overall on the normal passage $(16.7 \%)$ than on the asterisk passage $(10.2 \%)$. Importantly, as was predicted, there was a significant interaction of passage format and type of test word $\left[F(1,34)=12.54, M S_{\mathrm{e}}=171, p<.01\right]$. Whereas the asterisks had essentially no overall impact on the detection of the letter "a" in other words, they greatly enhanced detection of the letter "a" in the word "a." This decrease in letter detection errors on the word "a" when it was surrounded by asterisks provides support for the hypothesis that individuals read the word " $\mathrm{a}$ " in a unit that

Table 1

Letter Detection Error Percentages in Experiment 1 as a Function of Passage Format and Type of Test Word

\begin{tabular}{ccc}
\hline Passage & \multicolumn{2}{c}{ Type of Test Word } \\
\cline { 2 - 3 } Format & "a" & Other Words \\
\hline Normal & 18.8 & 14.6 \\
Asterisk & 4.5 & 15.8 \\
\hline
\end{tabular}


extends beyond the word boundary to include the interword spaces.

\section{EXPERIMENT 2}

In Experiment 1, as is predicted by the unitization account, the subjects made a smaller percentage of letter detection errors on the word "a" in passages with asterisks replacing the interword spaces than in passages typed normally, presumably because the asterisks disrupted the familiar visual configuration of the larger unit. This is a surprising finding, because earlier studies suggest that asterisks would hide or mask the target letter through lateral interference, rather than increase its visual saliency (see, e.g., Estes et al., 1976). Thus, Experiment 1 provides a strong confirmation of the unitization account.

However, there are three possible alternative explanations for the surprising findings in Experiment 1. First, perhaps the reduction in letter detection errors on the word "a" when asterisks, rather than blank spaces, surrounded it was due to the fact that the subjects used different global reading strategies when reading passages with asterisks and passages with normal spaces. Experiment 2 was designed to test this alternative explanation. As well as replicating Experiment 1 by manipulating the presence of asterisks between passages (i.e., comparing pure passages containing either only normal interword spaces or only asterisks in the interword spaces), Experiment 2 also manipulated the interword space variable within passages (i.e., mixed passages were used that contained, within a given passage, both normal interword spaces and asterisks in the interword spaces). Under the assumption that a single global reading strategy would be used throughout a short text (although this assumption may be questioned because, even in a short text, there may be moment-to-moment shifts in reading strategy as a function of local changes in the text), the same strategy would necessarily be used when the word "a" was surrounded by asterisks and when it was surrounded by blank spaces in the mixed passages. Only the unitization explanation, not the alternative global reading strategy explanation, could explain the finding with the mixed passages that the percentage of letter detection errors on the word "a" was smaller when that word was surrounded by asterisks than when it was surrounded by blank spaces.

There is a second possible alternative account for the finding, in Experiment 1, of fewer errors on the word "a" when it occurred in a passage with asterisks than when it occurred in a passage with normal spaces. According to this task-specific strategy explanation, subjects given passages in the asterisk format noticed that whenever the asterisk-letter-asterisk pattern appeared, the letter was a target and, hence, they chose to scan for this pattern. However, this account suffers from two problems. First, it cannot explain why a parallel strategy was not used with passages in the normal format, because subjects given such passages could equally well have noticed that whenever the blank-letter-blank pattern appeared, the letter was a target. Second, all interword spaces were replaced by asterisks in the passages in the asterisk format. Thus, all the words were surrounded by asterisks, so it does not seem reasonable that the subjects would have employed a strategy in which they scanned for a pattern involving asterisks, rather than the target letter itself. In any event, such a task-specific strategy should be less likely to be used with the mixed passages in Experiment 2.

There is a third possible alternative explanation for the results of Experiment 1 that involves the type font employed (Times New Roman). This type font uses proportional spacing, so that wide letters and characters take up more area than do narrow letters and characters (e.g., the letters $w w w$ take up more area than the letters iii). As a consequence, the interword space in Experiment 1 was somewhat larger in the asterisk condition (because it was filled with an asterisk) than in the normal condition (because it was blank). To correct this problem in Experiment 2, we used a different type font (Courier), in which every letter, character, and space occupies the same size area.

\section{Method}

Subjects. The subjects were 48 students ( 28 women and 20 men) from St. Lawrence University, who were enrolled in three different sections of an introductory psychology course and who volunteered to participate for extra class credit. Five additional subjects were tested, but their data were not analyzed, because they did not follow the instructions.

Design. A $2 \times 2 \times 2$ mixed factorial design was employed, with one between-subjects variable, passage format type (mixed and pure passages), and two within-subjects variables, type of interword space (normal and asterisk) and type of test word ("a" and other words). The dependent variable was the percentage of letter detection errors.

Materials. Each subject read the same two passages as those used in Experiment 1. However, unlike Experiment 1, the passages were prepared in Courier type font, with a font size of 10, to ensure that the size of the interword spaces was the same when they were left blank and when they contained asterisks.

Each passage was prepared in four formats, two pure and two mixed. The pure formats corresponded to the normal and asterisk formats used in Experiment 1. Exactly half of the interword spaces were replaced with asterisks in each passage in the mixed formats, with the locations of the asterisks selected pseudorandomly. Specifically, for the mixed formats, a single passage included both normal (i.e., without filler characters) interword spaces and interword spaces filled with asterisks. In each of the two mixed formats, four of the instances of the test word "a" were surrounded by asterisks $\left(* a^{*}\right)$, and the other four were surrounded by normal interword spaces ( a ). Likewise, in each of the two mixed formats, eight of the instances of the other test words were surrounded by asterisks, and the other eight were surrounded by normal interword spaces. In addition, in each mixed format, half of the remaining interword spaces in the passage were replaced by asterisks, and the other half were normal. Across the two mixed formats of each passage, a given interword space occurred once replaced by an asterisk and once as usual. As in Experiment 1, there were no extra asterisks at the end or beginning of a line, and there was only a single space (or asterisk) separating a period from the first word of the next sentence. The word "a" never occurred as the first or last word on a line. 
The subjects were given photocopies of the two passages. For the subjects in the pure passage format group, the same counterbalancing procedures were used as those in Experiment 1. For the subjects in the mixed passage format group, analogous counterbalancing procedures were used. Specifically, half of the subjects saw the passages in the order Passage A then Passage B, and the other half saw the passages in the reverse order. For each of these groups of subjects, there were two counterbalancing subgroups such that, across subgroups, each of the two mixed formats used with a given passage was shown equally often.

The test packets were the same as those in Experiment 1, except for the format of the passages in the mixed passage format group.

Procedure. The subjects were tested in four separate groups in the same classroom at different times. The students were assigned to passage format type groups and to counterbalancing groups and subgroups according to a fixed rotation depending on their time of arrival for testing.

\section{Results and Discussion}

Performance on the four multiple-choice comprehension questions was very good. The mean percentage of comprehension errors was $7.8 \%$, which also compares favorably with an error rate of $75 \%$ based on guessing.

The results of Experiment 2 are summarized in Table 2 in terms of percentages of letter detection errors as a function of passage format type, type of interword space, and type of test word. There was a significant main effect of type of interword space $\left[F(1,46)=17.40, M S_{\mathrm{e}}=146, p<\right.$ $.01]$. The subjects made more errors overall on words surrounded by blank spaces $(18.1 \%)$ than on words surrounded by asterisks $(10.8 \%)$. Importantly, as was predicted, there was a significant interaction of type of interword space and type of test word $\left[F(1,46)=7.41, M S_{\mathrm{e}}=\right.$ $147, p<.01]$. Whereas the asterisks had essentially no overall impact on the detection of the letter "a" in other words (normal, $17.7 \%$; asterisk, $15.2 \%$ ), they greatly enhanced detection of the letter "a" in the word "a" (normal, $18.4 \%$; asterisk, 6.4\%). This decrease in letter detection errors on the word "a" when it was surrounded by asterisks mimicked the decrease shown in Experiment 1 and provided additional support for the hypothesis that individuals read the word "a" in a unit that extends beyond the word boundary to include the interword spaces. Because the same pattern of results was found across the mixed and pure passages, the effect of asterisk cannot be attributed to global reading strategy differences across passage formats.

Table 2

Letter Detection Error Percentages in Experiment 2 as a Function of Passage Format Type, Type of Interword Space, and Type of Test Word

\begin{tabular}{ccc}
\hline Interword & \multicolumn{2}{c}{ Type of Test Word } \\
\cline { 2 - 3 } Space & "a" & Other Words \\
\hline \multicolumn{3}{c}{ Mixed Passage Format } \\
Normal & 19.0 & 20.5 \\
Asterisk & 8.5 & 18.1 \\
\multicolumn{3}{c}{} \\
Normal & Pure Passage Format \\
Asterisk & 17.9 & 15.0 \\
\hline
\end{tabular}

\section{EXPERIMENT 3}

Experiment 2 provided additional support for the unitization explanation and evidence against the three alternative explanations that had been proposed for the findings in Experiment 1. Letter detection errors on the word "a" were reduced when that word was surrounded by asterisks, rather than by blank spaces, even in the mixed passage format. Hence, the reduction cannot be explained by different global reading strategies when passages with asterisks and passages with normal spaces are read. Further, Courier type font was used in Experiment 2, so the reduction in letter detection errors on the word " $a$ " when it was surrounded by asterisks, rather than by blank spaces, cannot be explained by an increase in the size of the interword spaces when the spaces were filled with asterisks, rather than left blank. Finally, finding the reduction of detection errors on the word "a" when that word was printed as "*a*" rather than as " a " cannot be explained by a task-specific strategy of looking for the asterisk-letter-asterisk pattern, because the reduction was equally large in the mixed passage format as in the pure passage format, although the strategy would be less likely to apply to the mixed passage format.

However, there is a possible alternative explanation for the results. The reduction in letter detection errors on the word "a" when asterisks, rather than blank spaces, surround it can be explained with the assumption that subjects can ignore the asterisks because they do not resemble regular letters, so that regular letters pop out when they are surrounded by asterisks (e.g., $I{ }^{*}$ was $^{*} a * h o{ }^{*}$ day. ${ }^{*}$ The ${ }^{*}$ girl ${ }^{*}$ took). The present experiment was designed to test this alternative explanation. Instead of including an asterisk in each interword space, the lowercase letter " $x$ " was included. Because " $x$ " is a regular letter, it cannot be ignored, and other letters should not pop out when surrounded by it (e.g., Itxwasxaxhotxday.xThexgirlxtook). In fact, because the letter " $x$ " is a short letter, like the letter " $a$," it seems especially unlikely that the letter "a" should pop out when surrounded by instances of the letter " $x$ " (i.e., compare * $a$ * and $x a x$ ). Thus, only the unitization explanation, not the alternative, pop out explanation, could explain a finding that the number of letter detection errors on the word "a" was smaller in the present experiment when that word was surrounded by instances of the letter " $x$ " than when it was surrounded by blank spaces.

\section{Method}

Subjects. The subjects were 16 students ( 7 women and 9 men) from the University of Colorado. All but one of these students were enrolled in a course on experimental methods in psychology and volunteered to participate as part of a class exercise. The remaining subject, who was tested individually, was also a student at the University of Colorado but was not in the experimental methods course. One additional subject from the experimental methods course was tested, but her data were not analyzed, because she did not follow the instructions. 
Design. A $2 \times 2 \times 2$ mixed factorial design was employed, with one between-subjects variable, passage format order (normal first, $x$ first), and two within-subjects variables, type of interword space (normal and $\mathrm{x}$ ) and type of test word ("a" and other words). The dependent variable was the percentage of letter detection errors.

Materials. As in Experiments 1 and 2, each subject saw two passages, the same ones that were used in Experiments 1 and 2. They were prepared in Courier type font, with a font size of 10, as in Experiment 2 . The letter " $x$ " did not occur in any of the words in these passages.

The passages were prepared in two formats. The normal format was typed in the regular fashion, with no asterisks present, whereas the $\mathrm{x}$ format was typed with a lowercase " $\mathrm{x}$ " replacing every interword space. There was no extra " $x$ " at the end or beginning of a line, and there was only a single space (or an " $x$ ") separating a period from the first word of the next sentence. The word "a" never occurred as the first or last word on a given line.

The subjects were given photocopies of the two passages. The same counterbalancing procedures were used as those in Experiment 1 and in pure passages in Experiment 2. The test packets were the same as those in Experiment 1, except that the x passages replaced the asterisk passages.

Procedure. The subjects were tested in one large group in a classroom, with the exception of 1 subject, as was noted earlier. The students were assigned to passage format order groups and passage order subgroups according to a fixed rotation depending on their seat in the classroom.

\section{Results and Discussion}

Performance on the four multiple-choice comprehension questions was very good. The mean percentage of comprehension errors was $5.5 \%$, which well exceeded any expectation based on guessing.

The results of Experiment 3 are summarized in Table 3 in terms of percentages of letter detection errors as a function of passage format and type of test word. There was a significant main effect of passage format $[F(1,14)=$ $\left.28.96, M S_{\mathrm{e}}=86, p<.01\right]$. The subjects made more errors overall on the normal passage $(20.9 \%)$ than on the asterisk passage (8.4\%). Importantly, as was predicted, there was a significant interaction of passage format and type of test word $\left[F(1,14)=12.26, M S_{\mathrm{e}}=156, p<.01\right]$. Whereas the instances of the letter " $x$ " had very little overall impact on the detection of the letter "a" in other words, they greatly enhanced detection of the letter "a" in the word "a." There was one additional significant interaction involving passage format and passage format order $\left[F(1,14)=10.21, M S_{\mathrm{e}}=86, p<.01\right]$. This interaction reflects the fact that errors on the normal passage were greater when the $x$ passage came first $(28.1 \%)$ than when the normal passage came first $(13.7 \%)$, whereas errors on the $\mathrm{x}$ passage did not vary appreciably as a function of passage format order (x passage first, $8.2 \%$; normal pas-

Table 3

Letter Detection Error Percentages in Experiment 3 as a Function of Passage Format and Type of Test Word

\begin{tabular}{crc}
\hline \multirow{2}{*}{ Passage } & \multicolumn{2}{c}{ Type of Test Word } \\
\cline { 2 - 3 } Format & "a" & Other Words \\
\hline Normal & 27.3 & 14.5 \\
$\mathrm{x}$ & 3.9 & 12.9 \\
\hline
\end{tabular}

sage first, 8.6\%). Importantly, there was no three-way interaction of passage format, type of test word, and passage format order $(p>.10)$, because the crucial interaction of passage format and type of test word was obtained for both passage format orders. The decrease in letter detection errors on the word "a" when it was surrounded by instances of the letter " $x$ " resembles that found in Experiment 1 with asterisks (in fact, the effect was even larger in this case, primarily because detection errors on the word "a" were exceptionally high in the normal format). This finding bolsters the evidence for the hypothesis that individuals read the word "a" in a unit that extends beyond the word boundary to include the interword spaces. It could be argued that replacing the interword spaces with the letter " $x$ " has a phonological or orthographic effect because "xax" can be read as a pronounceable syllable. However, because the same pattern of results was found for instances of the letter " $\mathrm{x}$ " as had been found for asterisks, neither this explanation nor the alternative, pop-out explanation seems likely.

\section{GENERAL DISCUSSION}

This series of experiments provides support for the hypothesis that for the very common word " $a$," readers can use a processing unit that extends beyond the word boundary to include the interword spaces. This support comes from the finding that filling in the interword spaces with irrelevant characters (either asterisks or instances of the letter " $x$ ") led to a severe reduction in the percentage of letter detection errors in the case of the word "a" but led to little or no overall reduction in the percentage of letter detection errors in the case of other words containing the target letter "a." This result, which was found when the presence of asterisks was manipulated both between and within passages, is surprising and unique because, as far as we know, it is the only case in which hiding or masking a target in extraneous irrelevant noise, thus making it less visually salient, actually improves detection of that target.

A possible alternative explanation for finding reduced detection errors on "a" when it is surrounded by irrelevant characters, relative to when it is surrounded by blank spaces, is that subjects read the passages in the asterisk or $\mathrm{x}$ format more slowly and/or with less attention to content than the passages in the normal format. However, this global strategy explanation is ruled out for two reasons. First, although the subjects made a much smaller percentage of letter detection errors with the asterisk or $\mathrm{x}$ format than with the regular format on the word "a," there was essentially no overall decrease in letter detection errors for the asterisk or $\mathrm{x}$ format in any of the experiments on other words, despite the heterogeneity of these words. In Experiments 2 and 3, there were numerically more errors with the normal format than with the asterisk or x format on words other than "a." However, these differences were slight and were not statistically significant [Experiment $2, F(1,46)=1.52$, 
$M S_{\mathrm{e}}=100, p=.22$; Experiment $\left.3, F(1,15)<1\right]$. In contrast, there were large, statistically significant differences for the letter "a" [Experiment 2, $F(1,46)=18.07$, $M S_{\mathrm{e}}=193, p<.01$; Experiment 3, $F(1,15)=18.44$, $\left.M S_{\mathrm{e}}=238, p<.01\right]$. Second and most important, the subjects given mixed passages in Experiment 2 also made a much smaller percentage of letter detection errors on the word "a" when it was surrounded by asterisks than when it was printed normally with blank spaces around it. (Although changes in global reading strategies cannot explain the effect of filling the interword spaces around the word "a," global strategies may affect reading in other ways in these experiments. Note, for example, that the percentage of letter detection errors on other words with normal interword spaces was approximately $15 \%$ with the pure format in Experiments 1, 2, and 3 but was over $20 \%$ with the mixed format in Experiment 2.)

Another possible explanation could be proposed for finding a reduced percentage of detection errors on the word "a" when it was surrounded by asterisks, rather than by blank spaces. According to the pop-out explanation, the reduction in letter detection errors on the word "a" when asterisks, rather than blank spaces, surround it is due to the subjects' ignoring the asterisks because they do not resemble regular letters, so that regular letters pop out. On the basis of Experiment 3, we can be fairly confident that this explanation is unlikely. The letter " $\mathrm{x}$ " was used in Experiment 3, instead of an asterisk, in each interword space because " $x$ " is a regular letter and, thus, should not be ignored or cause other letters to pop out. Thus, only the unitization explanation, not the alternative, pop-out explanation, can explain the finding in Experiment 3 of a reduced percentage of detection errors on the word "a" in the x passage, relative to the normal passage.

The question arises as to how our account can explain why the subjects made fewer letter detection errors overall on the word "a" surrounded by asterisks or by instances of the letter " $x$ " than on other words, such as "walked," surrounded by the same irrelevant characters. The answer is that the character strings "*a*" and "xax" contained no sequence of characters that was familiar and, thus, these strings had to be read in units no larger than a single character. In contrast, the character strings "*walked*" and "xwalkedx" contained some familiar letter sequences (e.g., "walk"), and these sequences could be read in units larger than the letter (e.g., syllable units).

The word " $a$ " is very common, so that it can be read in a unit that incorporates the surrounding interword spaces and may be identified in the parafovea, whereas other less common words, such as "walked," may be read in letter or syllable units, but they may not be read in units that extend beyond the word boundary. According to our account, the size of the reading unit used for a given word depends most crucially on the familiarity of the unit or its frequency in the language. The word "a," like the word "the," is highly familiar and, thus, more likely than less common words to be read in a unit extending beyond the word boundary. Other factors that may be prerequisites for reading units extending beyond the word itself concern visual properties that impact the reader's ability to identify the units in the parafovea. These properties presumably include distinctive word shape and word length. Some investigators have argued that word shape does not play an independent role in word identification (see, e.g., Besner, 1989; Oden, 1984; Paap, Newsome, \& Noel, 1984). However, other studies (e.g., Healy \& Cunningham, 1992; Monk \& Hulme, 1983) have provided evidence that word shape is an important variable in recognizing familiar words. Thus, it is possible that beyond the requirement that a word be familiar, it must also have a distinctive shape in order for it to be identified in the parafovea. Furthermore, on the basis of eye movement studies showing that skipping (i.e., failing to fixate) a word is a function of word length (e.g., Blanchard, Pollatsek, \& Rayner, 1989; Rayner \& McConkie, 1976), another likely requirement for word identification in the parafovea is that the word be short. Thus, longer, less common words, such as "walked," would presumably require foveal fixation for identification. It has been shown that when words are fixated in foveal view, few letter detection errors are made on those words (even when they are highly familiar words, such as "the"), presumably because letter identification is facilitated in that case, so that word identification does not occur prior to letter identification (see, e.g., Hadley \& Healy, 1991).

Can it be demonstrated that the effect of interword spaces found for the word "a" is generalizable to other very common short words? The word "a" is the fifth most common word in the English language (Kučera \& Francis, 1967). There is, however, another word containing the target letter "a" that is even more commonnamely, the word "and" (which is the third most common word in English; Kučera \& Francis, 1967). The word "and" has the target letter in the first position, which is adjacent to the preceding interword space. The word "and" appeared twice in Passage B, occurring once with asterisks surrounding the interword spaces and once with normal interword spaces in both mixed formats of Experiment 2. We found little overall difference between words other than "a" surrounded by asterisks and those surrounded by normal interword spaces in the mixed passage format of Experiment 2 (see Table 2). Nevertheless, we conducted a post hoc comparison of the percentage of letter detection errors on "and" surrounded by both types of interword spaces (normal and asterisk) for subjects who received passages in the mixed format in Experiment 2. As had been found by Drewnowski and Healy (1977), the subjects made a very large percentage of detection errors on "and" surrounded by normal interword spaces (79.2\%). The percentage of detection errors on "and" surrounded by asterisks was significantly lower $[41.7 \% ; t(23)=3.71, p<.01]$. This finding, although post hoc, demonstrates that the effect of interword spaces found for the word "a" does indeed generalize to another short, common function word. It is also consistent with a similar finding for the word "and" 
when plus signs replaced the interword spaces (Healy \& Drewnowski, 1983, Experiment 3) and subjects searched for the target letter "n." Furthermore, a previous study by Healy et al. (1987, Experiment 2) showed a similar effect for the word "the" when subjects searched for the target letter "h." (Note that in both of these cases, the target letter was not adjacent to the interword space.) The extent to which this effect will generalize to other words varying in their length, familiarity, and word type (e.g., function or content words) is an empirical question that remains to be answered. Another, related open question is whether word size reading units always include the surrounding interword spaces or do so only for some words. In all three experiments of the present study, irrelevant characters surrounding a word did not lead to superior detection of letters in that word for other words as a group. Likewise, Healy and Drewnowski (1983) did not find a drop in detection errors on words other than "and" when plus signs replaced the interword spaces, even for the frequent suffix morpheme "-ing." Thus, it seems unlikely that the effect of interword spaces found for "a," "and," and "the" will generalize to most other words. It may be that only the highest frequency short words incorporate their surrounding spaces as part of their reading units, because only those words can be identified while in the parafovea and thus skipped (i.e., not fixated). However, even if the findings for "a," "and," and "the" do not generalize to any other words, they would be of interest as special cases demonstrating that reading units can extend beyond the word boundaries to include the surrounding interword spaces. Furthermore, although only 3 words are included in this set at this point, they account for more than $12 \%(122,060)$ of the words found in a million-word sample of text (Kučera \& Francis, 1967).

The results of the post hoc comparison with mixed passages in Experiment 2 for the word "and" (i.e., finding a very large percentage of detection errors on the common word "and" when it was typed normally, as well as a substantial reduction in detection errors on that word when it was surrounded by asterisks) also help explain another puzzling finding in this study. The percentage of detection errors on the word "a" was only slightly higher than the percentage of detection errors on other words in the normal passages in Experiments 1 and 2. The large percentage of errors on other words can be explained by the fact that all of the words in the prose passages were common (and even known to first-grade children) and that many of them (e.g., "and" and "at") were short as well. Hence, many of the other words may be read in units larger than a single letter, and some of the other words, like the word "a," may be read in units that include the surrounding interword space. Indeed a post hoc examination of the prose passages in Experiment 3 also revealed that there was a large percentage of detection errors on the word "and" for the normal format of Passage $\mathrm{B}(56.3 \%)$, as well as a substantial reduction in that percentage for the $\mathrm{x}$ format $[12.5 \% ; t(14)=3.13, p<.01]$.
In this study, we manipulated both interword spaces around a given word in the same way (i.e., both were normal or both were replaced with irrelevant characters). Hence, we cannot speak to the question of whether the preceding and following interword spaces surrounding a given word differ in terms of their relevance or importance to the reading unit. An asymmetry in the processing of information from the right and the left sides of a fixated word has been noted in studies of eye movement monitoring (e.g., Rayner, Well, \& Pollatsek, 1980); it has been shown that the effective visual field extends longer to the right than to the left of fixation. Furthermore, in the earlier study by Healy et al. (1987, Experiment 2), the interword space before the test word "the" was found to be more critical to the reading unit than the interword space after the word "the." A similar difference may be found for other words, including "a" and "and," but that remains a subject of further investigation.

Although the postlexical structural account of Koriat and Greenberg (1994) provides an alternative explanation for the large percentage of letter detection errors on frequent function words, this account has no mechanism by which to explain the effects of prelexical visual factors, which have been demonstrated in earlier experiments (e.g., Drewnowski \& Healy, 1977; Healy et al., 1987; Healy \& Drewnowski, 1983; Schneider \& Healy, 1993), as well as the effective manipulation of the visual format of the interword space in the present study. Recognizing this theoretical issue, Greenberg, Healy, Koriat, and Kreiner (2004) combined features of both structural and unitization accounts into a new integrated GO model, such that unitization processes play a major role in the initial stages of processing (i.e., prelexical and lexical), whereas structural processes dominate subsequent stages of processing (i.e., postlexical). Letter detection errors result from both initial and subsequent stages. By the GO model, the presence of irrelevant characters (e.g., asterisks or instances of the letter " $x$ ") would disrupt the process by which the reader establishes the structural frame of a text and would thereby enhance the reader's ability to detect letters.

An alternative, detailed, and quantitative account of the reading process has been proposed by McClelland and Rumelhart (1981; Rumelhart \& McClelland, 1982) in their interactive activation model. According to this model, as with the unitization assumptions of the GO model, parallel processing occurs at various hierarchical levels, including letter features, letters, and words. Unlike the GO model, the interactive activation model postulates that activation at one level automatically excites or inhibits processing at another level. In particular, this model assumes the existence of automatic excitatory feedback from the word level to the letter level. Because of this assumption, the interactive activation model can account for the often-cited word superiority effect found in tachistoscopic letter identification (whereby letters are identified more easily when they occur in words than when they occur alone or in nonwords; see, e.g., Reicher, 
1969). However, this model cannot account for the finding that subjects make a large number of letter detection errors on frequent function words, which is the major result obtained in numerous letter detection studies (see Healy, 1994, and Koriat \& Greenberg, 1994, for reviews). In addition, this model has no provision for the role of word shape in reading, and it does not presently consider any role of the interword space in reading.

The present study thus provides evidence that readers can process text in units that extend beyond the word boundary and include the surrounding interword spaces. However, the present study does not provide any evidence concerning whether the reading units extend as far as the surrounding words. The suggestion has been made (e.g., Drewnowski \& Healy, 1977) that highly familiar words can be read in multiple word units, such as phrases or word frames (e.g., "of the"). Although the present study by no means provides evidence against these larger units, it also does not provide any evidence for them. Nevertheless, the present study makes it clear that interword spaces may be an integral part of reading units, and this finding must be considered in the formulation of models of the reading process.

\section{REFERENCES}

BESNER, D. (1989). On the role of outline shape and word-specific visual pattern in the identification of function words: None. Quarterly Journal of Experimental Psychology, 41A, 91-105.

Blanchard, H. E., Pollatsek, A., \& RAYNer, K. (1989). The acquisition of parafoveal word information in reading. Perception \& Psychophysics, 46, 85-94.

Cunningham, T. F., Healy, A. F., Kanengiser, N., Chizzick, L., \& WILLITTS, R. L. (1988). Investigating the boundaries of reading units across ages and reading levels. Journal of Experimental Child Psychology, 45, 175-208.

DREWNOWSKI, A. (1978). Detection errors on the word the: Evidence for the acquisition of reading levels. Memory \& Cognition, 6, 403-409.

Drewnowski, A. (1981). Missing -ing in reading: Developmental changes in reading units. Journal of Experimental Child Psychology, 31, 154-168.

Drewnowski, A., \& Healy, A. F. (1977). Detection errors on the and and: Evidence for reading units larger than the word. Memory \& Cognition, 5, 636-647.

Estes, W. K., Allmeyer, D. H., \& Reder, S. M. (1976). Serial position functions for letter identification at brief and extended exposure durations. Perception \& Psychophysics, 19, 1-15.

Greenberg, S. N., Healy, A. F., Koriat, A., \& Kreiner, H. (2004). The GO model: A reconsideration of the role of structural units in guiding and organizing text on line. Psychonomic Bulletin \& Review, 11, 428-433.

Greenberg, S. N., Koriat, A., \& Vellutino, F. R. (1998). Age changes in the missing-letter effect reflect the reader's growing ability to extract the structure from text. Journal of Experimental Child Psychology, 69, 175-198.

HadLeY, J. A., \& Healy, A. F. (1991). When are reading units larger than the letter? A refinement of the unitization reading model. Journal of Experimental Psychology: Learning, Memory, \& Cognition, 17, 1062-1073.

HEALY, A. F. (1976). Detection errors on the word the: Evidence for reading units larger than letters. Journal of Experimental Psychology: Human Perception \& Performance, 2, 235-242.
Healy, A. F. (1994). Letter detection: A window to unitization and other cognitive processes in reading text. Psychonomic Bulletin \& Review, 1,333-344.

Healy, A. F., Conboy, G. L., \& Drewnowski, A. (1987). Characterizing the processing units of reading: Effects of intra- and interword spaces in a letter detection task. In B. K. Britton \& S. M. Glynn (Eds.), Executive control processes in reading (pp. 279-296). Hillsdale, N J: Erlbaum.

Healy, A. F., \& Cunningham, T. F. (1992). A developmental evaluation of the role of word shape in word recognition. Memory \& Cognition, 20, 141-150.

Healy, A. F., Cunningham, T. F., \& Healy, C. A. (1998, November). Even third graders use reading units larger than the word. Poster presented at the 39th Annual Meeting of the Psychonomic Society, Dallas.

HeAly, A. F., \& DrewnOwsKi, A. (1983). Investigating the boundaries of reading units: Letter detection in misspelled words. Journal of Experimental Psychology: Human Perception \& Performance, 9, 413426.

Koriat, A., \& GreEnBerg, S. N. (1994). The extraction of phrase structure during reading: Evidence from letter detection errors. Psychonomic Bulletin \& Review, 1, 345-356.

KUČERA, H., \& FrANCIS, W. N. (1967). Computational analysis of presentday American English. Providence, RI: Brown University Press.

McClelland, J. L., \& Rumelhart, D. E. (1981). An interactive activation model of context effects in letter perception: Pt. 1. An account of basic findings. Psychological Review, 88, 375-407.

MonK, A. F., \& HulME, C. (1983). Errors in proofreading: Evidence for the use of word shape in word recognition. Memory \& Cognition, 11, 16-23.

MORris, R. K., Rayner, K., \& Pollatsek, A. (1990). Eye movement guidance in reading: The role of parafoveal letter and space information. Journal of Experimental Psychology: Human Perception \& Performance, 16, 268-281.

ODEN, G. C. (1984). Dependence, independence, and emergence of word features. Journal of Experimental Psychology: Human Perception \& Performance, 10, 394-405.

O'REGAN, K. (1979). Saccade size control in reading: Evidence for the linguistic control hypothesis. Perception \& Psychophysics, 25, 501509.

PaAp, K. R., Newsome, S. L., \& Noel, R. W. (1984). Word shape's in poor shape for the race to the lexicon. Journal of Experimental Psychology: Human Perception \& Performance, 10, 413-428.

PollatseK, A., \& RaYNer, K. (1982). Eye movement control in reading: The role of word boundaries. Journal of Experimental Psychology: Human Perception \& Performance, 8, 817-833.

RAYNER, K., \& MCCONKIE, G. W. (1976). What guides a reader's eye movements? Vision Research, 16, 829-837.

RAYNER, K., MCCONKIE, G. W., \& Zola, D. (1980). Integrating information across eye movements. Cognitive Psychology, 12, 206-226.

RAYNer, K., \& PollatseK, A. (1989). The psychology of reading. Englewood Cliffs, NJ: Prentice-Hall.

Rayner, K., Sereno, S. C., Morris, R. K., Schmauder, A. R., \& Clifton, C. (1989). Eye movements and on-line language comprehension processes. Language \& Cognitive Processes, 4, 21-49.

Rayner, K., Well, A. D., \& Pollatsek, A. (1980). Asymmetry of the effective visual field in reading. Perception \& Psychophysics, 27, 537-544.

REICHER, G. M. (1969). Perceptual recognition as a function of meaningfulness of stimulus material. Journal of Experimental Psychology, 81,275-280.

RUMELHaRT, D. E., \& McClelland, J. L. (1982). An interactive activation model of context effects in letter perception: Pt. 2 . The contextual enhancement effect and some tests and extensions of the model. Psychological Review, 89, 60-94.

Schneider, V. I., \& Healy, A. F. (1993). Detecting phonemes and letters in text: Interactions between different types and levels of processes. Memory \& Cognition, 21, 739-751. 


\section{APPENDIX \\ Passages and Comprehension Questions Used in the Experiments}

\section{Passage A}

It was a hot day. The girl took her dog for a walk. They walked in the road. On the way she saw a man painting his house. It was a nice red color. She saw a boy playing in the park. She went to see him. He had a dog with him, too. It was a nice dog. They had a good time.

1. The girl took her dog for a walk. Where did they walk? (a) on the beach, (b) in the road, (c) on the rocks, (d) in the airport

2. What kind of day was it when the girl took her dog for a walk? (a) a cold day, (b) a rainy day, (c) a hot day, (d) a windy day

3. As she and her dog walked, the girl saw a man: (a) painting his house, (b) selling hot-dogs, (c) reading a newspaper, (d) flying a kite

4. The girl met a boy in the park who also had a dog. It was: (a) an ugly dog, (b) a huge dog, (c) a little dog (d) a nice dog

\section{Passage B}

One day a girl went to the park with her Mom to play. They wanted to take a walk. They saw a tree, a fish, and a rabbit on the way. The girl played with a boy and a dog at the park. They all had a good time.

1. The girl went to the park with her: (a) Mom, (b) Dad, (c) sister, (d) brother

2. As they walked, they saw: (a) a deer, (b) a horse, (c) a hawk, (d) a rabbit

3. Whom did the girl play with at the park? (a) her classmates, (b) a boy, (c) another girl, (d) her father

4. When playing at the park, the girl had: (a) a fight, (b) a bad fall, (c) a good time, (d) lots to eat

(Manuscript received July 20, 1999;

revision accepted for publication December 8, 2003.) 